\title{
Thermal performance of corrugated plate heat exchanger using ethylene glycol as test fluid
}

Battula SREEDHAR RAO, Chittireddy KEERTHANA REDDY, Pullurwar MEENA, Sriramoju KISHORE KUMAR

DOI: $10.30464 /$ jmee.2020.4.2.167

Cite this article as:

Sreedhar Rao B., et al. Thermal performance of corrugated plate heat exchanger using ethylene glycol as test fluid. Journal of Mechanical and Energy Engineering, Vol. 4(44), No. 2, 2020, pp. 167-172.

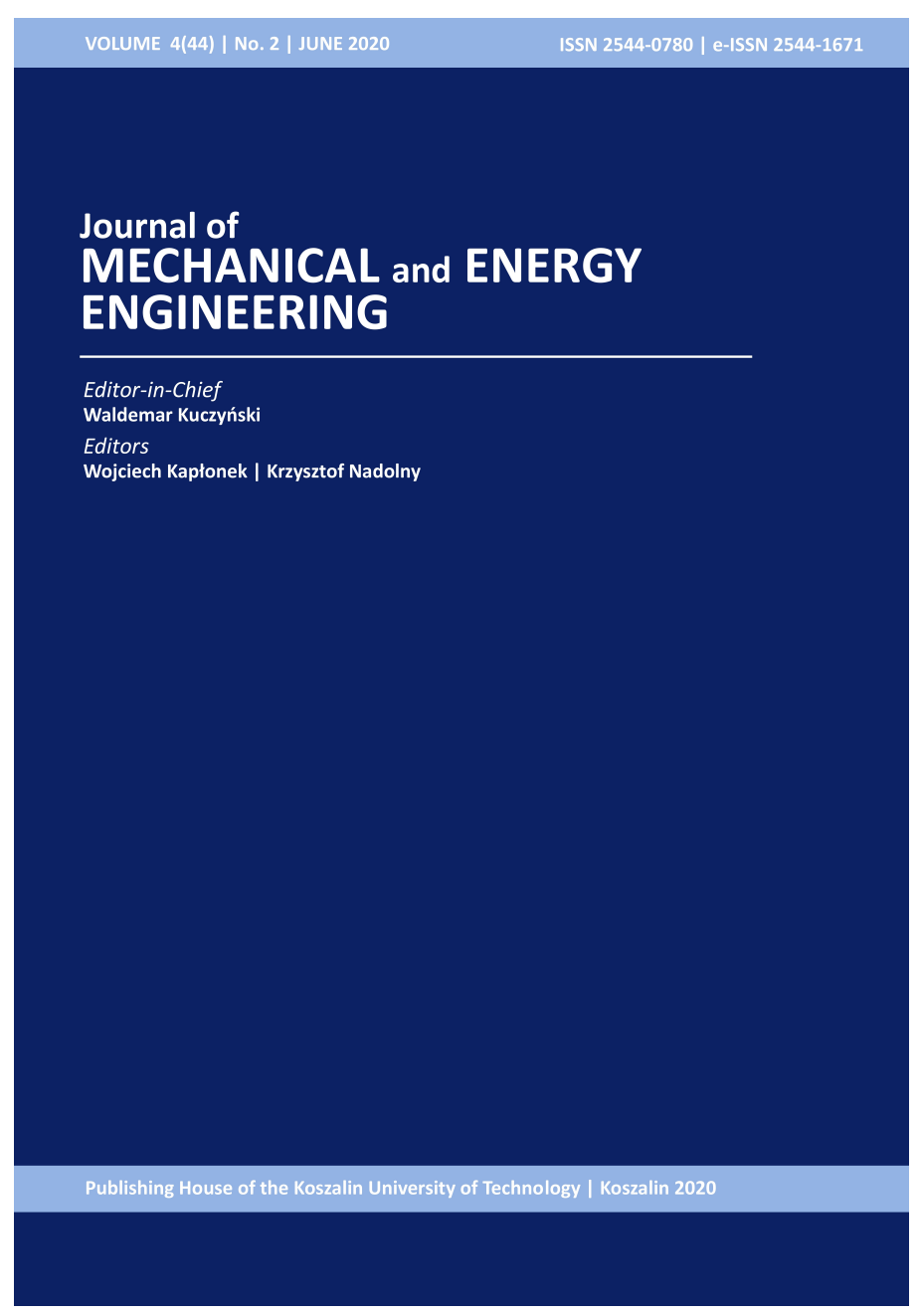

Journal of Mechanical and Energy

Engineering

Website: jmee.tu.koszalin.pl

ISSN (Print): 2544-0780

ISSN (Online): 2544-1671

Volume: $4(44)$

Number: 2

Year: 2020

Pages: $167-172$

Article Info:

Received 15 July 2020

Accepted 26 July 2020

\section{Open Access}

This article is distributed under the terms of the Creative Commons Attribution 4.0 (CC BY 4.0) International License (http://creativecommons.org/licenses/by/4.0/), which permits unrestricted use, distribution, and reproduction in any medium, provided you give appropriate credit to the original author(s) and the source, provide a link to the Creative Commons license, and indicate if changes were made. 


\title{
THERMAL PERFORMANCE OF CORRUGATED PLATE HEAT EXCHANGER USING ETHYLENE GLYCOL AS TEST FLUID
}

\author{
Battula SREEDHAR RAO ${ }^{1}$, Chittireddy KEERTHANA REDDY ${ }^{1}$, Pullurwar MEENA ${ }^{1}$, \\ Sriramoju KISHORE KUMAR ${ }^{* 1}$ \\ ${ }^{1 *}$ Department of Chemical Engineering, Chaitanya Bharathi Institute of Technology, Hyderabad, T.S., India. \\ e-mail: kishoresriramoju@gmail.com, kishorekumar_chem@cbit.ac.in
}

(Received 15 July 2020, Accepted 26 July 2020)

\begin{abstract}
This paper reports an experimental comparative thermal analysis of a flat plate heat exchanger and corrugated plate heat exchanger (CPHE) of different corrugation angles using ethylene glycol as test fluid. The experiments were carried out in counter current mode using water as hot fluid at $75^{\circ} \mathrm{C}$. Design of each plate provided with eleven thermocouple sensors to determine the temperatures, in which seven were used to measure the surface temperature of plate and four were used to measure the inlet and outlet bulk temperature of cold and hot fluids. The mass flow rate of test fluid, varied between 0.5 to 4 liters per minute and corresponding steady state temperatures is measured. Using experimental readings, temperature difference between the inlet and outlet streams $(\Delta T)$, logarithmic mean temperature difference (LMTD) and overall heat transfer coefficient $(U)$ are determined. The obtained $\Delta T$ and $U$ values of corrugation angles $\left(30^{\circ}, 50^{\circ}\right)$ of CPHE were compared with those of flat plate heat exchangers. For corrugation angle of $30^{\circ}$ and $50^{\circ}$, the $\Delta T$ and $U$ values increases with increase of mass flow rate of the fluid. The turbulence in the flow increases due to increase in the corrugation angle, which results in the enhancement of heat transfer. Moreover, thermal effectiveness $(\varepsilon)$ is estimated using NTU method and compared for all the plates. As the $N_{R e}$ values gradually increases, $\varepsilon$ decreases for flat plate and CPHE $\left(\theta=30^{\circ}\right.$ and $\left.\theta=50^{\circ}\right)$. At low $N_{R e}$ value of 114 , observed a maximum $\varepsilon(\cong 0.998)$ value for corrugated angle of $50^{\circ}$. There is adequate contact time between the cold and hot fluids at low Reynolds number, so maximum rate of heat transfer is possible, as a result $\mathcal{E}$ values are high.
\end{abstract}

Keywords: corrugated plate heat exchanger, overall heat transfer coefficient, effectiveness, Reynolds number

\section{INTRODUCTION}

Heat exchangers are thermal devices employed in diverse industrial applications to heat or cool of process fluids. The hot and cold fluids are separated by a thermal conductive surface, so that both fluids cannot mix in the heat exchanger. A wide variety of such exchangers are employed in thermal power stations, air condition devices, automotive, chemical, bio and pharma industries, Oil and petroleum industries, sewage treatment, waste heat recovery systems. Their design and type of heat exchanger depends on the parameters such as type of process fluid, thermal efficiency, space availability and cost. Such industries explore for heat exchanger with small occupied area, high thermal performance and low investment. Corrugated plate heat exchanger belongs to such category because it can retrieve effective heat at small temperature due to high turbulence created at low velocities $[1,2]$.

Many experimental [3-14] and simulation study [15-21] shows that the rate of heat transfer enhance with using of corrugated plate heat exchanger (CPHE). The experimental investigation on CPHE for single phase flow of Reynolds number ranging from 500 to 2500 had shown an enhancement in heat transfer coefficient and they derived correlations between Nusselts number and Reynolds number [3]. In CPHE with parallel flow using water as fluid at small temperature difference by varying the space between the plates and observed that 
the optimal heat transfer possible at a minimum spacing of $6 \mathrm{~mm}$ [4]. The corrugated plate of corrugation angle increases $\left(30^{\circ}, 40^{\circ}\right.$ and $\left.50^{\circ}\right)$, heat transfer rate also increases because it a offers higher surface area of contact as well as turbulence in the flow [5-7]. Furthermore, as the angle of corrugations is reaches to $50^{\circ}$, creates more turbulence in the flow regimes which ultimately improves heat transfer rate also severely pressure drop [2, 8-10]. Moreover, the plate design of CPHE, additionally improves the mechanical strength to heat exchanger [11]. Experiments are conducted for various corrugation angles of $30^{\circ}, 40^{\circ}$ and $50^{\circ}$ with wavy type corrugated plate heat exchanger to understand the difference factors that affecting the flow, such as, energy losses, frictional factors and pressure drop using glycerol as test fluid [5,12]. Optimization studies are conducted on the corrugated type of gasketed-plate heat exchanger using dairy milk [13]. The researchers also performed numerical studies to analyze the heat transfer mechanism and fluid flow regimes using CFD tools with flat plate heat exchanger and corrugated plate heat exchanger [15-20]. The advantage using CFD study is that, the temperature can be measured at any particular point in the model is possible. Many of them developed the correlations on the heat transfer coefficient as well as Nusselts number as a function of Reynolds number using PHE $[16,17]$ and CPHE [18-20]. Recently, CFD simulation performed with modification design of CPHE shown improved thermal performance and effectiveness with water-water as test fluid [20]. They also proved that there is up to $75 \%$ increment in the Nusselts number as compared with normal CPHE.

While most studies focus on CPHE are limited to either air or water as the test fluid $[4,15,18-20]$. This paper focuses to maximization of heat transfer of ethylene glycol using CPHE. To investigate the heat transfer enhancement in the corrugated plate heat exchanger, estimated the overall heat transfer coefficient and thermal effectiveness of corrugated plate heat exchanger for different corrugated angles. Moreover, these values are compared with flat plate heat exchanger. In this work EG is used as test fluid because it has low thermal conductivity alcohol. EG had wide spread applications such as industrial antifreeze, coolant for gas compressors, heating, chilledwater air-conditioning systems.

\section{METHOD}

The experimental setup used for the investigation of heat transfer consist of flat plate heat exchanger and corrugated plate heat exchangers (CPHE) as the display in Figure 1. The corrugated plate is designed with plate length of $0.3 \mathrm{~m}$, width of $0.1 \mathrm{~m}$ and channel spacing of $0.005 \mathrm{~m}$. The CPHE of corrugation angles $\left(\theta=30^{\circ}\right.$ and $50^{\circ}$ ) measured with reference to the horizontal plane as shown in Figure 2. The experimental setup additionally consists of hot and cold fluid storage tanks that are separately connected with pump and rotameter. Eleven thermocouple sensors provided in the overall set-up to measure the temperatures at different locations. To measure the surface temperatures of the plates, seven thermocouples are placed along the length of each plate. In addition, four thermocouple sensors were inserted to record the temperature of inlet and outlet of test fluid and hot fluid. In this study measuring devices such as thermocouples and rotameters used in the experimental setup with their range and error associated with it are shown in Table 1. The experiments are performed in counter flow arrangement in which test fluid is passed through the bottom channel and hot fluid is passed through the top channel of corrugated plate. Water at $75^{\circ} \mathrm{C}$ is taken as hot fluid and Ethylene glycol is used as a test fluid. The fluid mass flow rate of test fluid changed between $0.5 \mathrm{lpm}$ to $4 \mathrm{lpm}$ in the step change of $0.5 \mathrm{lpm}$ and the temperatures at eleven positions were noted after reaching the steady state. Using measured temperatures, calculated temperature difference $(\Delta \mathrm{T})$ of inlet and outlet of the fluid. Using energy balance of hot and cold fluids, calculated the logarithmic mean temperature difference (LMTD). Using LMTD, estimated the overall heat transfer coefficient (U) for all type of plate heat exchangers. A set of three experiments are performed for each flow rate to calculate the values and the same averaged and plotted. The detailed procedures of the calculations of several heat transfer components are given below.

Tab. 1. Accuracy of measuring devices used in the experiment with the range of parameter and error

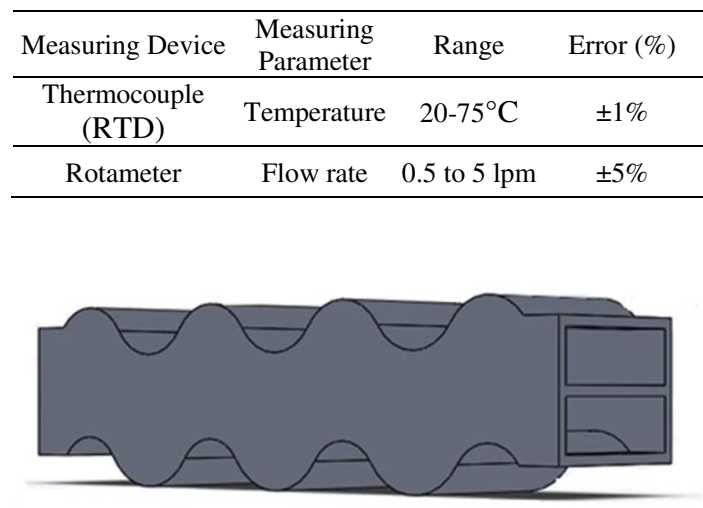

Fig. 1. Schematic design of corrugated plate

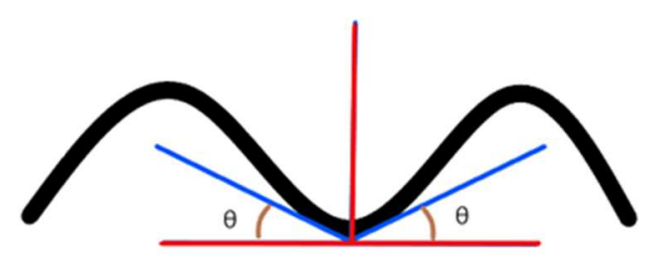

Fig. 2. Schematic of Corrugated angle $(\theta)$ taken for corrugated plate 
Using energy balancing equation for heat exchanger: Heat transfer rate for hot fluid:

$$
Q h=m h C p h(t h 1-t h 2) \text {. }
$$

Heat transfer rate for cold fluid:

$$
Q c=m c C p c(t c 1-t c 2) \text {. }
$$

In this experiment the fluids flow in counter current mode, then Logarithmic mean temperature difference is calculated by:

$$
\Delta T_{L M T D}=\frac{\left(T_{\text {avg }}-T_{c, \text { in }}\right)-\left(T_{\text {avg }}-T_{c, \text { out }}\right)}{\ln \frac{T_{\text {avg }}-T_{c, \text { in }}}{T_{\text {avg }}-T_{c, \text { out }}}},
$$

Where, $T_{c, \text { in }}$ and $T_{c, \text { out }}$ are the inlet and outlet temperature $(K)$ of test fluid respectively. And $C_{p}$ is specific heat capacity $(\mathrm{KJ} / \mathrm{KgK})$. Total heat transfer:

$$
Q=\frac{Q_{h}+Q_{c}}{2} .
$$

Overall heat transfer coefficient $(U)$ can be expressed as:

$$
U=\frac{Q}{A . \Delta T_{L M T D}} .
$$

The heating effectiveness $(\varepsilon)$ of heat exchanger is a measure of actual rate of heat transfer to maximum possible rate and it is calculated by Number of transfer unit (NTU) method [21]:

$$
N T U=\frac{U \cdot A}{m_{c .} C_{p c}} .
$$

Capacity ratio:

$$
\mathrm{C}_{\mathrm{r}}=\frac{\mathrm{m}_{\mathrm{C}} \mathrm{C}_{\mathrm{c}}}{\mathrm{m} \cdot \mathrm{C}_{\mathrm{h}}}
$$

Effectiveness:

$$
\varepsilon=\frac{1-\mathrm{e}^{\left(1-C_{\mathrm{r}}\right)} \cdot \mathrm{NTU}}{1-\mathrm{C}_{\mathrm{r}} \cdot \mathrm{e}^{\left(1-C_{\mathrm{r}}\right) \cdot \mathrm{NTU}}} .
$$

\section{RESULTS AND DISCUSION}

The experiments are performed using ethylene glycol as test fluid in the laminar flow region $\left(1025<N_{R e}\right)$ with a flat plate heat exchanger, corrugated plate heat exchanger (CPHE) with corrugation angle of $30^{\circ}$ and $50^{\circ}$. An essential parameter and driving force for heat transfer of any heat exchanger is difference in temperature of process fluids. Moreover, heat transfer is directly proportional to the magnitude of temperature gradient. The Figure 3 depicts the temperature difference $(\Delta T)$ in ${ }^{\circ} \mathrm{C}$ with variation of mass flow rate for ethylene glycol. It can be observed that for flat plate heat exchanger, as the mass flow rate changes, there is no significant change in the temperature difference. For CPHE, the effective increase in $\Delta T$ is noted for a specific corrugation angle. And also it can be observed that the maximum increment in the temperature is possible with corrugation angle of $50^{\circ}$.

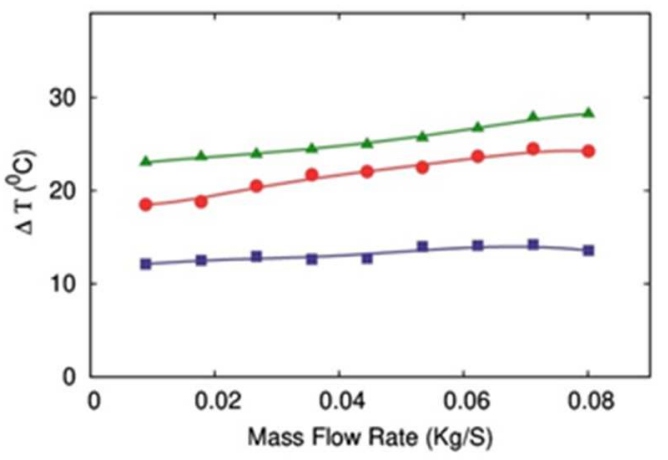

Fig. 3. Variation in Temperature gradient $(\Delta T)$ with mass flow rate $(\mathrm{Kg} / \mathrm{s})$ of test fluid for flat plate heat exchanger (blue square) and corrugated plate heat exchanger with corrugation angle of $30^{\circ}$ (red circle), $50^{\circ}$ (green triangle)

The performance of any heat exchanger can also describe by the overall heat transfer coefficient because it plays a vital role in the design. In the overall heat transfer coefficient $(U)$ includes all type of resistances that are present in the part of thermal transfer. Moreover, the rate of heat transfer is directly proportional to the $U$, so the larger $U$ value indicates, higher rate of heat transfer. The influence of fluid mass flow rate on overall heat transfer coefficient of a flat plate heat exchanger, different corrugation angles of CPHE is shown in figure 4. It is clear that, for flat plate there is no significant effect on $\mathrm{U}$ at a low mass flow rate, and as the mass flow rate increases a small enhancement in $\mathrm{U}$ is observed. But for corrugation angle of $30^{\circ}$ and $50^{\circ}$, the $\mathrm{U}$ increases with increase of mass flow rate of the test fluid. Furthermore, for any value of mass flow rate, the overall heat transfer coefficient is maximum for corrugation angle of $50^{\circ}$. A small change in the corrugation angle causes turbulence in the flow, which ultimately leads to intensified the $U$. And this turbulence is maximum for high corrugation angles, which resulting in enhancement of $U$. For corrugation angle of $50^{\circ}$, high $\mathrm{U}$ value is indicated at mass flow rate of $0.08 \mathrm{~kg} / \mathrm{s}$. These results are excellent agreement with past studies on CPHE with different fluids [2, 8-10, 19].

Furthermore, to investigate the performance of CPHE, thermal effectiveness $(\varepsilon)$ is estimated using NTU method, which compares the actual rate of heat transfer to maximum possible rate [21]. The variation of thermal effectiveness as a function of Reynolds number $\left(N_{R e}\right)$ for a flat plate and CPHE displayed in Figure 5. According to the figure, as the $\mathrm{N}_{\mathrm{Re}}$ values gradually increases, $\varepsilon$ decreases for flat plate and CPHE ( $\theta=30^{\circ}$ and $\left.\theta=50^{\circ}\right)$. Furthermore, at low $\mathrm{N}_{\mathrm{Re}}$ values, the effectiveness is higher for all type of plates. At $\mathrm{N}_{\mathrm{Re}}$ values of 114 , the value of $\varepsilon$ reached the maximum ( $\varepsilon \cong 0.998$ ) for a corrugated angle of $50^{\circ}$. Calculated 
values are fitted with following second order polynomial equations with $\mathrm{R}$-square is greater than 0.9 .

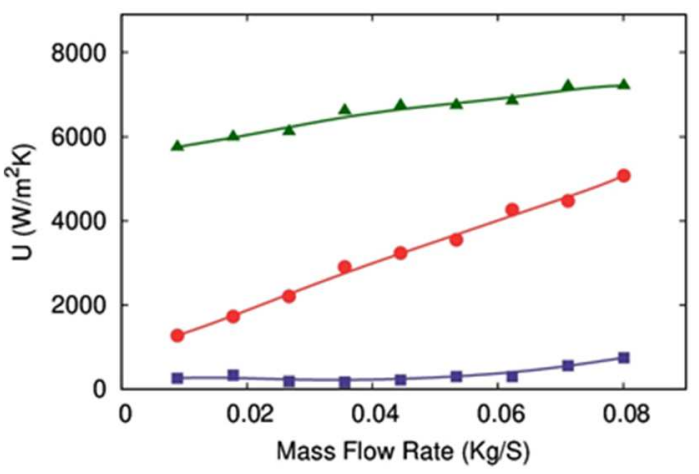

Fig. 4. Universal heat transfer coefficient $(U)$ versus mass flow rate of test fluid for flat plate heat exchanger (blue square) and corrugated plate with corrugation angle of $30^{\circ}$ (red circle), $50^{\circ}$ (green triangle)

For flat plate:

$\varepsilon=7 \cdot 10^{-07}\left(N_{R e}\right)^{2}-0.001\left(N_{R e}\right)+0.3849$.

For CPHE $\theta=30^{\circ}$ :

$$
\varepsilon=5 \cdot 10^{-07}\left(N_{R e}\right)^{2}-0.009\left(N_{R e}\right)+0.8853 .
$$

For CPHE $\theta=50^{\circ}$ :

$$
\varepsilon=1 \cdot 10^{-07}\left(N_{R e}\right)^{2}-0.007\left(N_{R e}\right)+1.1049 .
$$

The equations indicate decrease in slopes i.e., act as resistance to the heating effectiveness with increase of Reynolds number. Obviously, at low Reynolds number, there is adequate time of contact between the test fluid and hot fluids, which improves the rate of heat transfer, as a result $\varepsilon$ values are high. In contrast, at high Reynolds number due to contact time laps between the hot and cold fluids the effectiveness gradually decreases.

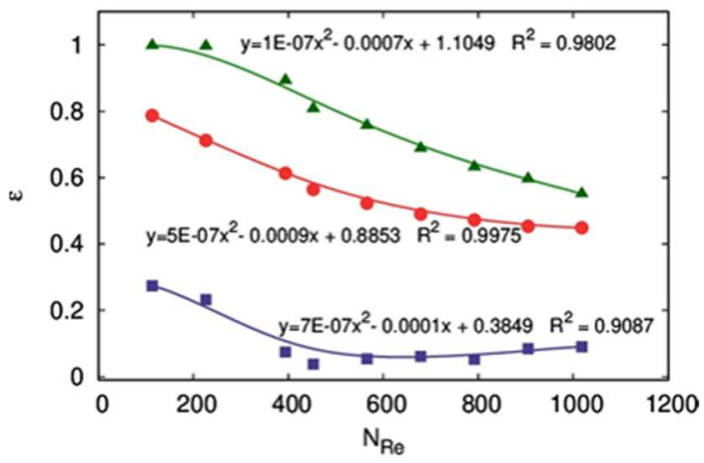

Fig. 5. Comparision of heating effectiveness $(\mathcal{E})$ as a function of Reynolds number $\left(N_{R e}\right)$ for flat plate (blue square), corrugated plate with corrugation angle $\theta=30^{\circ}$ (red circle) and $\theta=50^{\circ}$ (green triangle)

\section{CONCLUSIONS}

A performance analysis of a flat plate heat exchanger and corrugated plate heat exchanger (CPHE) with corrugation angle of $30^{\circ}$ and $50^{\circ}$ for different flow configuration has been performed by using ethylene glycol as test fluid. The effects of changing mass flow rate from $0.5 \mathrm{lpm}$ to $4 \mathrm{lpm}$ of all types of plate exchangers on the rate of heat transfer, overall heat transfer coefficient and effectiveness have been studied. With increase in the flow rate the temperature difference $(\Delta T)$ of the test fluid and overall heat transfer coefficient $(U)$ increases, and it is maximum in case of CPHE with corrugation angle of $50^{\circ}$. Increase in corrugation angle generates more turbulence in the flow regime, as a result, significant enhancement in the $\Delta T$, $\mathrm{U}$ as well as rate of heat transfer observed. In contrast, for flat plate as the flow rate increases, there is no significant change in $\Delta \mathrm{T}$ and $\mathrm{U}$ is observed. The heating effectiveness of flat plate and CPHE decreases with increase of Reynolds number. Correlations derived between $\varepsilon$ and $N_{R e}$ from the curve fitting with second order polynomial equation, shows decrease in the slopes, indicates a resistance to effectiveness as of increases the Reynolds number because, laps in the contact time between the hot and cold fluid. At $N_{R e}$ value of 114 , a larger value of $\varepsilon \cong 0.998$ is observed for a corrugated angle of $50^{\circ}$.

\section{Acknowledgements}

The authors pleasure to acknowledge the authorities of Chaitanya Bharathi Institute of Technology (C.B.I.T.), Hyderabad, India and for providing experimental facilities that have contributed to the research results reported within this paper.

\section{Nomenclature}

\section{Symbols}

$\mathrm{Cp} \quad-\quad$ Specific heat capacity $(\mathrm{KJ} / \mathrm{KgK})$

$\mathrm{C}_{\mathrm{r}} \quad-$ Capacity ratio

$\mathrm{C}_{\mathrm{ph}} \quad-\quad$ Specific heat capacity $(\mathrm{J} / \mathrm{K})$

$\theta \quad-$ Corrugation angle (Degree)

$\varepsilon \quad-\quad$ Thermal Effectiveness

h $\quad-$ Heat transfer coefficient $\left(\mathrm{W} /\left(\mathrm{m}^{2} \mathrm{~K}\right)\right)$

$\mathrm{K} \quad-$ Thermal conductivity $\left(\mathrm{KW} / \mathrm{m}^{2} \mathrm{~K}\right)$

$\mathrm{m}_{\mathrm{c}} \quad-\quad$ Mass flow rate of fluid $(\mathrm{kg} / \mathrm{s})$

$\mathrm{m}_{\mathrm{h}} \quad-$ Mass flow rate of hot fluid $(\mathrm{kg} / \mathrm{s})$

$\mathrm{N}_{\mathrm{Re}} \quad-\quad$ Reynolds number

$\mathrm{U}$ - Overall heat transfer coefficient, $\left(\mathrm{W} /\left(\mathrm{m}^{2} \mathrm{~K}\right)\right.$

$\mathrm{Q}_{\mathrm{h}} \quad$ - Heat transfer for hot fluid (W)

$\mathrm{Q}_{\mathrm{c}} \quad$ - Heat transfer for cold fluid (W)

$\mathrm{T}_{\mathrm{h} 1} \quad-\quad$ Temperature of hot fluid (K)

$\mathrm{T}_{\mathrm{h} 2} \quad-\quad$ Temperature of hot fluid (K)

$\mathrm{T}_{\mathrm{cl} 1} \quad-\quad$ Temperature of cold fluid $(\mathrm{K})$

$\mathrm{T}_{\mathrm{c} 2} \quad-\quad$ Temperature of cold fluid $(\mathrm{K})$

Tc,in - Temperature of cold fluid inlet $(\mathrm{K})$

Tc,out - Temperature of cold fluid outlet (K) 


\section{Acronyms}

CPHE - Corrugated plate heat exchanger

LPM - Liters per minute-flow rate

LMTD - log mean temperature cold difference

NTU - Number of transfer unit

\section{References}

1. Nishimura T., Murakami S., Arakawa S., Kawamura Y. (1990), Flow observations mass transfer characteristics in symmetrical wavy walled channel at moderate Reynolds numbers for steady flow, International Journal of Heat and Mass Transfer, vol. 33, pp. 835-845.

2. Wanakulasuriya F. S. K., Worek W. M. (2008), Heat transfer and pressure drop properties of high viscous solutions in plate heat exchangers, International Journal of Heat and Mass Transfer, vol. 1, no. 51, pp. 52-67.

3. Khan T. S., Khan M. S., Ming-C. Chyu,et al. (2010), "Experimental investigation of single phase convective heat transfer coefficient in a corrugated plate heat exchanger for multiple plate configurations." Applied Thermal Engineering ; 30(8-9): 1058-1065.

4. Faizal M., \& Ahmed M. R. (2012), Experimental studies on a corrugated plate heat exchanger for small temperature difference applications. Experimental Thermal and Fluid Science, 36: 242-248.

5. Sreedhara Rao B., Mayuri M., Krishna Kant D., Himanshu V, Murali Krishna M. V. S. and Sastry R. C. (2015). Heat Transfer Studies In Wavy Corrugated Plate Heat Exchangers, I.J.A.R.E.T., 6(11), pp. 72-79.

6. Heggs P. J., Sandham P., Hallam R. A., Walton C. (1997), Local transfer coefficient in corrugated plate heat exchanger channels, 5th UK National Heat Transfer Conference, vol. 75, no. 7.

7. SreedharaRao B., Varun S., Surywanshi G. D., Sastry R C (2014), Experimental Heat Transfer Studies of Water in Corrugated Plate Heat Exchangers: Effect of Corrugation Angle, I.J.S.E.T., 3, pp. 9025.

8. Sreedhara Rao B., Mayuri M., Sarasija Y., Rohini G. and Sastry R. C. (2012), Pressure drop studies in wavy corrugated plate heat exchangers, International Journal of Mechanical Engineering and Technology, 6 (12), pp. 60-65.

9. Sreedhara Rao B., Surywanshi G. D., Varun S., Murali Krishna M.V.S. and Sastry R. C. (2015), Effects of corrugation angles on heat transfer studies of viscous fluids in Corrugated Plate Heat Exchangers, International Journal of Engineering and Technology Innovation, vol. 5, no. 2, pp. 99-10.

10. Durmuş A., Gül H., Kurtbaş I. and Benli H. (2009), Investigation of heat transfer and pressure drop in plate heat exchangers having different - surface profiles. International journal of heat and mass transfer, 52(5), pp.1451-1457.

11. Gut J.A.W., Pinto J.M. (2004), Optimal configuration design for plate heat exchangers, International Journal of Heat and Mass Transfer 47, pp. 4833-4848.

12. Murali Krishna M.V.S., Omkar swamy M.B., Majunath G.H., Venkateswara Rao N., Sreedhara Rao B. and Krishna Murthy P.V. (2016), Heat Transfer Enhancement in - Corrugated Plate Heat Exchanger, British Journal of Applied Science \& Technology 18(3), pp.1-14.

13. N.P. Thakkar and M. Kumar (2019), Performance analysis and Optimization of plate type heat Exchanger in dairy industries, PDPU Journal of Energy and Management, Vol. 3, No.2, pp.11-20.

14. Sreedhara Rao B, Srilekha M., Sai prafulla T., Chinmayi P., Kishore Kumar S (2020). "Heat Transfer Enhancement of Ethylene Glycol using Corrugated Plate Heat Exchanger" International Journal of Innovative
Technology and Exploring Engineering, Volume-9 Issue4, pp 325-328.

15. Kanaris Athanasios G., Aikaterini A. Mouza, and Spiros V. Paras (2006) "Flow and heat transfer prediction in a corrugated plate heat exchanger using a CFD code." Chemical Engineering \& Technology, 29(8): 923-930.

16. Lin J.H, Huang C.Y. (2007), Dimensional Analysis for Heat transfer Characterisitcs in Corrugated channels Flat Plate Heat Exchangers, International Communication in Heat and MassTransfer, 34, pp304-312.

17. Jorge A.W.G., Jose M. P. (2003), Selecting optimal configurations for multi section plate heat exchangers in pasteurization processes,. Ind. Eng. Chem. Res, 42(24), pp.6112-6124.

18. Anjibabu D., Nayeem S. (2019), Heat Transfer Phenomenon of Fluids in Corrugated Plate Heat Exchangers, I.J.E.A.T., Volume: 8, Issue-5, 2019, p.p 975978.

19. Zahrani S. Al, Islam M.S., Saha S.C. (2019), Thermohydraulic characteristics investigation in corrugated plate heat exchanger, Energy Procedia, 160, pp.597-605.

20. Zahrani S. Al, Islam M.S., XU F., Saha S.C. (2020), Thermal Performance investigation in a novel corrugated plate heat exchanger, International journal of heat and mass transfer, 148, pp.119095.

21. Frank K., Raj M.M. and Mark S.B. (2011), Principles of heat transfer, $7^{\text {th }}$ Edition, Cengage Learning. tamford, USA, p.p.506-515.

\section{Biographical notes}

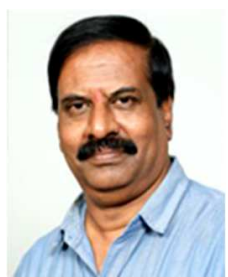

Sreedhara Rao Battula received his Ph.D. in Chemical Engineering from National Institute of Technology (N.I.T.) Warangal, India, in 2015. Currently he works as an associated professor and HOD in Chemical engineering department, at C.B.I.T. Hyderabad, Telangana, India. His areas of research include Heat transfer, Surface coatings and paints. He has publication in various $\mathrm{SCI} / \mathrm{Scopus}$ indexed journals, as well as conference proceedings.

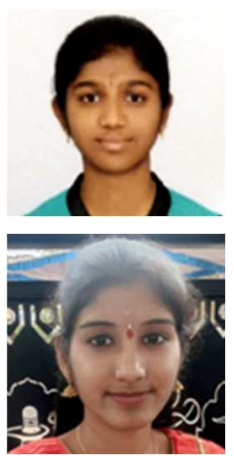

Keerthana Reddy Chittireddy is pursuing final semester of B.Tech. in Chemical Engineering at C.B.I.T. Hyderabad, Telangana, India. Her area of research interest is Heat transfer.

Meena Pullurwar is pursuing final semester of B.Tech. in Chemical Engineering at C.B.I.T. Hyderabad, Telangana, India. Her area of research interest is Heat transfer.

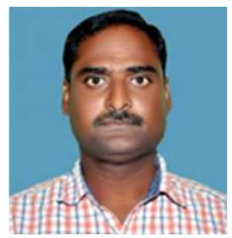

Kishore Kumar Sriramoju received his M.Tech and Ph.D. in Chemical Engineering from Indian Institute of Technology (I.I.T.) Kharagpur, India. in 2012 and 2017 respectively. Currently he works as an assistant professor in Chemical engineering department at C.B.I.T. Hyderabad, Telangana, India. His areas of research include Heat transfer, Polymer nanocomposites, Reaction Kinetics. He has publication in various SCI/Scopus indexed journals, as well as conference proceedings. 
